\title{
Morphology and Formation Mechanism of Dendritic Inclusions in Iron and Iron-Nickel Alloys Deoxidized with Silicon and Solidified Unidirectionally*
}

\author{
By Noriyoshi ARITOMI** and Koki GUNJI**
}

\begin{abstract}
Synopsis
The morphology of inclusions in $\mathrm{Fe}$ and $\mathrm{Fe}-\mathrm{Ni}$ alloys, which were deoxidized with $0.1 w 6$ of $\mathrm{Si}$ and solidified unidirectionally under specified conditions, have been investigated. Dendritic inclusions were frequently observed in ingots containing a large amount of $\mathrm{O}$, but hardly in ingots whose $\mathrm{O}$ content was smaller than the amount equilibrating to the amount of $\mathrm{Si}$ at the liquidus temperature. The dendritic inclusions were classified roughly into two types: one is those existing mainly in the intercellular or interdendritic region of matrix, and the other is those grown from a spherical primary inclusion. By electron probe microanalyses and selected-area transmission electron diffraction experiments on the dendritic inclusions, it was confirmed that they were composed of silica or silicate and substantially amorphous. The dendritic inclusions seemed to be formed by a suitable gradient of a sufficient degree of supersaturation, which was caused mainly by the segregation of $\mathrm{O}$ andior caused by supercooling during solidification of $\mathrm{Fe}$.
\end{abstract}

\section{Introduction}

In the research on the deoxidation mechanism during solidification of $\mathrm{Fe}$, it is important to study the shape, size, distribution and composition of the deoxidation products in $\mathrm{Fe}$ solidified under controlled conditions. On the shape of inclusions in $\mathrm{Fe}$ deoxidized with $\mathrm{Si}$, some different shapes besides the ordinary spherical one have been reported by several investigators. ${ }^{1-9)}$ For example, Zapffe and Sims, ${ }^{1}$ ) Fischer and Wahlster, ${ }^{3)}$ Turpin and Elliott, ${ }^{4)}$ Forward and Elliott ${ }^{5)}$ and Hosoda et al. ${ }^{9)}$ have shown "raspberry" or "rosette" shape of inclusions. Forward and Elliott ${ }^{5}$ ) also reported rod-like "eutectic" inclusions. Hilty and Crafts $^{2)}$ and Sakagami et al..$^{6,7)}$ have shown dendritic inclusions; the latter ${ }^{6,7)}$ described that the dendritic inclusions were the secondary inclusions formed at the interdendritic region of matrix, and that the "raspberry" inclusions should be perhaps regarded as the secondary inclusions nucleated at a spherical inclusion and precipitated in the interdendritic region of matrix. Myers and Flemings $^{8)}$ have shown multimembered or irregularly shaped silica inclusions in an $\mathrm{Fe}-50 \% \mathrm{Cu}$ alloy, and suggested the possibility that the primary inclusions are pushed ahead of the dendrite arms and collide with one another during dendritic solidification.

For the purpose of obtaining some fundamental information about the deoxidation mechanism during solidification of $\mathrm{Fe}$, the present work aimed to clarify the formation mechanism of dendritic inclusions in $\mathrm{Fe}$ deoxidized with $\mathrm{Si}$. The morphology of inclusions in $\mathrm{Fe}, \mathrm{Fe}-10 \% \mathrm{Ni}$ and $\mathrm{Fe}-40 \% \mathrm{Ni}$ alloys, which were deoxidized with $0.1 \mathrm{wt}^{\mathrm{o}} \%$ of $\mathrm{Si}$ and solidified unidirectionally under specified conditions, are presented together with a discussion on the formation mechanism of dendritic inclusions.

\section{Experimental}

\section{Materials}

Three kinds of materials, Fe, Fe-10\% Ni and Fe$40 \% \mathrm{Ni}$ alloys, were mainly used in this experiment. $\mathrm{Fe}-10 \% \mathrm{Ni}$ alloy was used by the following reasons: (1) To estimate the cooling velocity during unidirectional solidification from the solidification structures of the ingot, because the relation between the cooling velocity and the dendrite arm spacing of the alloy is relatively clear, ${ }^{\mathbf{1 0}, 11)}$ and (2) The activity of $\mathrm{O}$ in $\mathrm{Fe}$ does not greatly change by the addition of $\mathrm{Ni}{ }^{12)} \mathrm{Fe}-40 \% \mathrm{Ni}$ alloy was used to examine the effects of, for example, the reduction of both the liquidus temperature and the saturation amount of $\mathrm{O}$ in the liquid by $\mathrm{Ni}$ addition, ${ }^{13,14)}$ on the morphology of deoxidation products.

Electrolytic Fe, of which the contents of C, Si, $\mathrm{Mn}, \mathrm{S}$ and $\mathrm{P}$ were less than $0.005 \mathrm{wt} \%$ respectively, and the electrolytic Fe mixed with 10 or $40 \mathrm{wt} \%$ of Mond nickel were melted in a high-frequency induction vacuum furnace, deoxidized to some degree with C, and cast into $5 \mathrm{~kg}$ ingots, respectively. They were hot-rolled into $16 \mathrm{~mm} \phi$ bars. The bars were cut into pieces of about $10 \mathrm{~cm}$ long and machined into a shape having a shallow hole on the plane surface of the one end: the diameter in the portion until $15 \mathrm{~mm}$ from the other end was $13 \mathrm{~mm}$ and that in the remaining portion $14 \mathrm{~mm}$. Each of the pieces weighed about $100 \mathrm{~g}$. They were used as the raw materials for unidirectional solidification. Their chemical compositions are shown in Table 1.

\section{Unidirectional Solidification of Ingot}

The apparatus used for unidirectional solidification of ingot is schematically shown in Fig. 1. The raw material was fixed vertically by inserting and soldering its bottom end in a pit bored on the upper sur-

Table 1. Chemical compositions of raw materials

\begin{tabular}{c|l|ccccc}
$\begin{array}{c}\text { Mate- } \\
\text { rial }\end{array}$ & $\begin{array}{c}\text { Main } \\
\text { constituent }\end{array}$ & \multicolumn{5}{|c}{ Composition $(w t \%)$} \\
\hline $\mathrm{A}$ & $\mathrm{Fe}$ & $\mathrm{O}$ & $\mathrm{C}$ & $\mathrm{S}$ & $\mathrm{N}$ \\
\hline $\mathrm{B}$ & $\mathrm{Fe}-10 \% \mathrm{Ni}$ & 10.12 & 0.036 & 0.004 & 0.005 & 0.0023 \\
$\mathrm{C}$ & $\mathrm{Fe}-40 \% \mathrm{Ni}$ & 39.37 & 0.012 & 0.002 & 0.004 & 0.0010
\end{tabular}




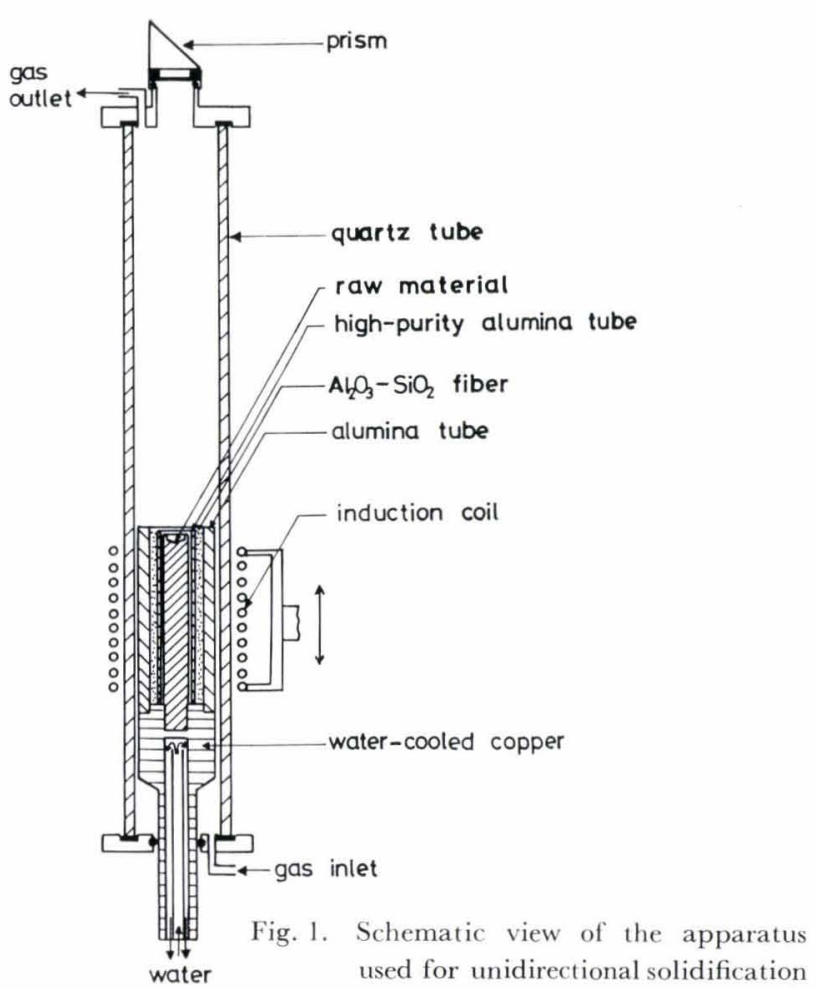

face of water-cooled copper, and surrounded with a high-purity alumina tube $\left(99.5 \% \mathrm{Al}_{2} \mathrm{O}_{3}\right)$ of $16 \mathrm{~mm}$ inner diameter. The high-purity alumina tube was surrounded still one more larger alumina tube, and $\mathrm{Al}_{2} \mathrm{O}_{3}-\mathrm{SiO}_{2}$ fibers were filled in the space between the two. Si was charged in the shallow hole on the top of raw material as an $\mathrm{Fe}-75 \% \mathrm{Si}$ alloy. They were encapsuled with a quartz tube of $45 \mathrm{~mm}$ inner diameter. After the air in the quartz chamber was evacuated, purified $3 \% \mathrm{H}_{2}-\mathrm{Ar}$ gas was introduced to and flowed through the chamber at a rate of $50 \mathrm{~cm}^{3} / \mathrm{min}$. The raw material was melted with a high-frequency (100 or $400 \mathrm{kHz}$ ) induction heating coil (16 turns), which was set at a proper position around the quartz tube. Temperature of the top surface of the material was measured with a color ratio pyrometer through a prism. From the temperatures measured at the beginning of melting or solidifying of $\mathrm{Fe}$, the errors of the temperature measurement seemed to be within $\pm 10^{\circ} \mathrm{C}$ at around the melting point of $\mathrm{Fe}$. The material was heated up to about $120^{\circ} \mathrm{C}$ above its liquidus temperature within $30 \mathrm{~min}$, maintained at the temperature for $10 \mathrm{~min}$, and then the induction heating coil was withdrawn upward, mostly at a constant speed of $1.7 \mathrm{~mm} / \mathrm{min}$. During the withdrawal of induction coil, the temperature of melt was controlled by the following two ways: i.e., (1) the induction heating power was gradually increased so that the temperature of melt might be kept at as constant as possible (represented by "T.C.", hereafter), and (2) the induction heating power was kept at constant (represented by "P.C.").

3. Determination of Solidification Conditions and Observation of Inclusions

For determining the rate of solidification dur- ing unidirectional solidification, $15 \sim 20$ pieces of $\mathrm{W}$ chips $(0.5 \mathrm{~mm} \phi \times 3 \sim 5 \mathrm{~mm})$ were thrown into the melt at suitable time intervals while the induction heating coil was withdrawing upward. Any temperature decrease of the melt caused by throwing W chips into the melt, was not observed. From the distances between the $W$ markers measured on the longitudinal cross section of the ingot and time intervals when $\mathrm{W}$ chips were thrown into the melt, the rates of solidification at respective positions of the ingot were determined.

The cooling velocities were estimated from the primary dendrite arm spacings observed at specified positions of ingots of material $\mathrm{B}$, by reference to a relation between the cooling velocity and the dendrite arm spacing of $\mathrm{Fe}-\mathrm{Ni}$ alloys. ${ }^{11}$ )

Several specimens were cut from specified positions of the unidrectionally solidified ingot. After the distribution and size of inclusions were determined on the mechanically polished cross section of the specimen with an optical microscope, the specimen was deeply etched electrolytically with a methyl-alcoholic solution containing $10 \%$ of acetyl-aceton and $1 \%$ of tetramethyl ammonium chloride, ${ }^{15)}$ followed by rinsing with alcohol, drying and coating a thin gold film by vacuum deposition, and then observed with a scanning electron microscope.

The constituents of inclusions were determined with an electron probe microanalyser. Selected-area transmission electron diffraction experiments were also performed on the inclusions, which were extracted from the deeply etched specimens by an extraction replica technique, with two types of electron microscopes: the accelerating voltage of one is $150 \mathrm{kV}$ and that of the other $500 \mathrm{kV}$.

\section{Results}

1. Macrostructure and Chemical Composition of Unidirectionally Solidified Ingot

All of the ingots solidified by the above-mentioned method had a unidirectionally solidified structure from the initial solid-liquid interface up to $2 \sim 4 \mathrm{~cm}$ above it. An example of the macrostructure of longitudinal cross section of such ingots is shown in Photo. 1 (a). The $\mathrm{O}$ and $\mathrm{Si}$ contents of twelve kinds of ingots used in this experiment are shown in Table 2. Their analyses were performed on samples taken from specified positions of the ingot. The $\mathrm{O}$ contents of some ingots suggest that there is a macrosegregation of $\mathrm{O}$ in the ingots. The $\mathrm{O}$ content of ingot $\mathrm{A}-1$ is much larger than that of the raw material; the reason is not clear. The contents of $\mathrm{Al}, \mathrm{Mn}, \mathrm{S}, \mathrm{Pb}$ and $\mathrm{Sn}$ in all ingots were $<0.001 \mathrm{wt} \%, 0.001 \sim 0.002 \mathrm{wt}^{\%}, 0.004 \sim$ $0.005 w \mathrm{t} \%, \quad 0.002 \mathrm{wt} \%$ and $0.003 \sim 0.004 \mathrm{wt} \%$, respectively. From this, it is obvious that the contamination by alumina crucible or solder is negligible.

2. Solidification Conditions during Unidirectional Solidification

Photograph 1 (b) shows an example of longitudinal cross section of ingot used to determine the rate of 


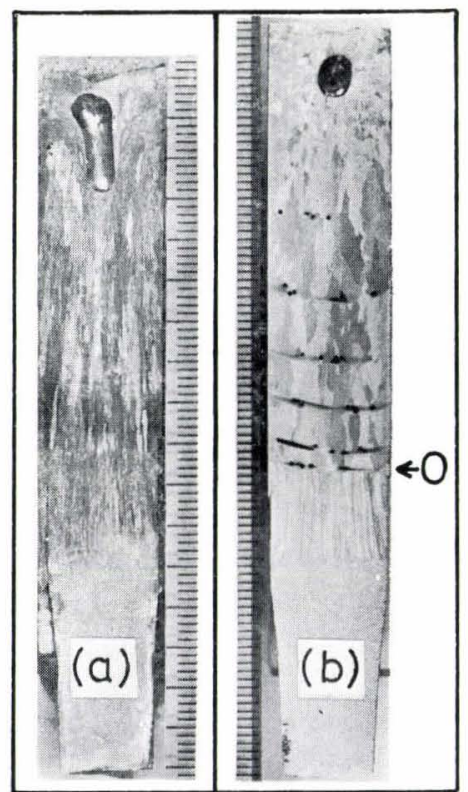

Unit of scale: $\mathrm{mm}$

Photo. 1. Macrostructures of longitudinal cross section of (a) ingot A-1, and (b) an ingot of material A used to determine the rate of solidification. "O " shows the initial solid-liquid interface.

Table 2. $\mathrm{O}$ and Si contents of unidirectionally solidified ingots* (wt \%)

\begin{tabular}{|c|c|c|c|c|c|c|}
\hline \multirow{2}{*}{$\begin{array}{l}\text { Ingot } \\
\text { No. }\end{array}$} & \multirow{2}{*}{$\begin{array}{l}\text { Solidifi- } \\
\text { cation } \\
\text { condi- } \\
\text { tion** }\end{array}$} & \multirow{2}{*}{$\begin{array}{l}\text { Amount } \\
\text { of } \\
\mathrm{Fe}-75 \% \mathrm{Si} \\
\text { charged } \\
\text { (g) }\end{array}$} & \multicolumn{2}{|c|}{$\mathrm{O}$} & \multicolumn{2}{|c|}{$\mathrm{Si}$} \\
\hline & & & $\frac{15 \sim}{20 \dagger}$ & $\underset{30+}{25 \sim}$ & $\begin{array}{l}5 \sim \\
15+\end{array}$ & $\begin{array}{r}15 \sim \\
25 \dagger\end{array}$ \\
\hline A-1 & \multirow{2}{*}{ T.C. } & 0 & 0.047 & 0.065 & 0.003 & 0.001 \\
\hline A-2 & & 0.1 & 0.011 & 0.010 & 0.089 & 0.098 \\
\hline$A-3$ & \multirow{2}{*}{ P.C. } & 0 & 0.014 & 0.014 & 0.001 & 0.002 \\
\hline A-4 & & 0.1 & 0.0037 & 0.0022 & 0.11 & 0.10 \\
\hline B-I & \multirow{2}{*}{ T.C. } & 0 & 0.026 & 0.036 & 0.002 & 0.001 \\
\hline B-2 & & 0.1 & 0.011 & - & 0.090 & 0.096 \\
\hline B-3 & \multirow{2}{*}{ P.C. } & 0 & 0.0096 & 0.016 & 0.002 & 0.001 \\
\hline B-4 & & 0.1 & 0.0034 & 0.0056 & 0.084 & 0.081 \\
\hline C-1 & \multirow{2}{*}{ T.C. } & 0 & 0.011 & 0.010 & 0.005 & 0.003 \\
\hline C-2 & & 0.1 & 0.0045 & 0.0042 & 0.12 & 0.11 \\
\hline C-3 & \multirow{2}{*}{ P.C. } & 0 & 0.0015 & 0.0068 & 0.003 & 0.003 \\
\hline C-4 & & 0.1 & 0.0023 & 0.0016 & 0.074 & 0.076 \\
\hline
\end{tabular}

* Frequency of induction power is $400 \mathrm{kHz}$ and the withdrawal speed of induction coil is $1.7 \mathrm{~mm} / \mathrm{min}$.

** Details of the solidification conditions are shown in Fig. 3.

+ Distance from the initial solid-liquid interface, $(\mathrm{mm})$

- Not determined

solidification. Examples of the relation between the rising distance of solid-liquid interface and the withdrawal distance of induction heating coil are shown in Fig. 2. Under the condition of T.C., the solidliquid interface does not rise until the induction coil has been withdrawn upward by about $20 \mathrm{~mm}$, while under the condition of P.C., the solid-liquid interface begins to rise at a shorter withdrawal distance. From

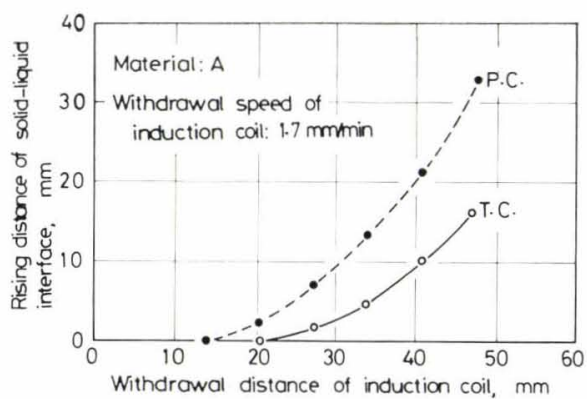

Fig. 2. Rising distance of solid-liquid interface $v$ s. the withdrawal distance of induction heating coil

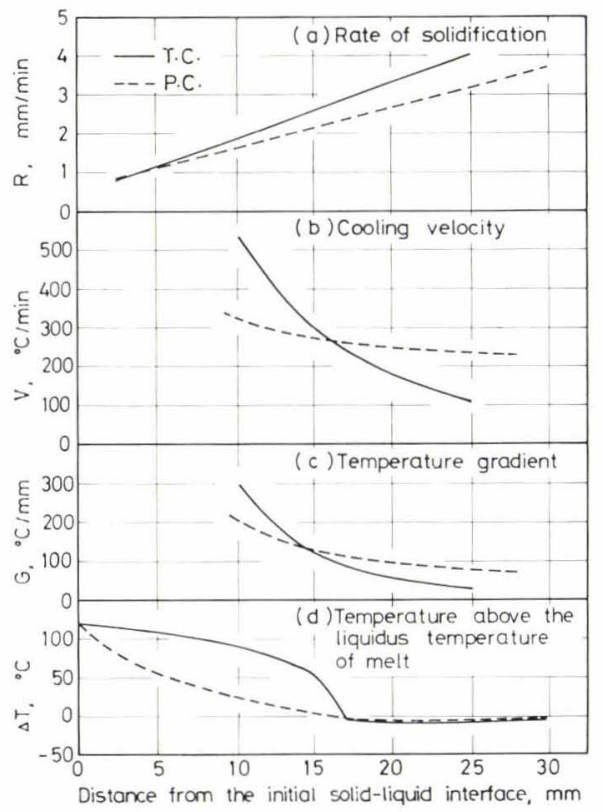

Fig. 3. Solidification conditions $v s$. the distance from the initial solid-liquid interface. Withdrawal speed of induction heating coil is $1.7 \mathrm{~mm} / \mathrm{min}$.

the tangent of the curve, the rates of solidification at any positions were determined. One to three experiments were carried out on each of the same kinds of materials $\mathrm{A}$ to $\mathrm{E}$, respectively. Materials $\mathrm{D}$ and $\mathrm{E}$ were $\mathrm{Fe}-5 \mathrm{wt} \% \mathrm{Mo}$ and $\mathrm{Fe}-0.2 \mathrm{wt} \% \mathrm{P}$ alloys, respectively, which were made by the same way as in the case of materials A to C. Any significant difference in the rate of solidification caused by the difference in the composition of materials, was not recognized. In the range of $2.5 \sim 25 \mathrm{~mm}$ from the initial solid-liquid interface, the rate of solidification varied almost linearly with the distance from the initial solid-liquid interface, and the slope of the straight line determined by the least squares method was slightly larger in the case of T.C. than in the case of P.C., as shown in Fig. 3 (a). Under both conditions, the rate of solidification coincides with the withdrawal speed of induction coil only at a position of about $10 \mathrm{~mm}$ from the initial solid-liquid interface.

The solidification structures in the region near the initial solid-liquid interface of both $B$ and $C$ series ingots, consisted of many densely arranged bands formed by so-called banding ${ }^{16)}$ and small rod-like cells between the bands. With increasing the distance 
from the initial solid-liquid interface, both the distance between the bands and the size of cell increased; such a structure is shown in Photo. 2 (a). In ingots B-1, B-2, C-1 and C-2, which were solidified under the condition of T.C., the rod-like cells gradually changed into cellular dendrites having secondary arms (Photo. 2 (b)), and abruptly changed into equiaxed dendrites. While in ingots B-3, B-4, C-3 and C-4, the dendrites having distinct secondary arms were observed only in near the portion solidified lastly. Although the structures of the wide region of ingots, especially when they were solidified under the condition of P.C., consisted of cells, all of the cells observed in this experiment were regarded as the primary dendrites, because the cells changed continuously into cellular dendrites having secondary arms. The average values of 50 to 100 primary dendrite arm spacings were determined at specified positions in the columnar structure region beyond by about $10 \mathrm{~mm}$ from the initial solid-liquid interface of $\mathrm{B}$ series ingots. On the assumption that a relation between the primary dendrite arm spacing and the value of $m c(k-1) / V$ (where $m$ is the slope of liquidus line, $c$ is the concentration of $\mathrm{Ni}, k$ is the equilibrium distribution coefficient, and $V$ is the cooling velocity) of $\mathrm{Fe}-\mathrm{Ni}$ alloys $^{11}$ is applicable to the present range of the arm spacings, the arm spacings were converted into cooling velocities: the value of $m c(k-1)$ was taken to be $11^{\circ} \mathrm{C}^{111)}$ The variation of the estimated cooling velocity with the distance from the initial solid-liquid interface was approximated by a hyperbola by the least squares method, and is shown in Fig. 3 (b). The temperature gradient in front of the solid-liquid interface, $G$, was also estimated from the rate of solidification, $R$, and the cooling velocity, $V$, by the equation, $G=V \mid R,{ }^{16)}$ and is shown in Fig. 3 (c).

In the region beyond by about $15 \mathrm{~mm}$ from the initial solid-liquid interface, both the values of $V$ and $G$ tend to be larger in the case of P.C. than in the case of T.C. The reason is probably as follows: under the condition of T.C., when the solid-liquid interface began to rise, the induction heating coil had already been withdrawn to a considerably higher position; therefore, the power input into the material decreased rapidly, and the temperature of melt decreased steeply, as shown in Fig. 3 (d). Furthermore, as the

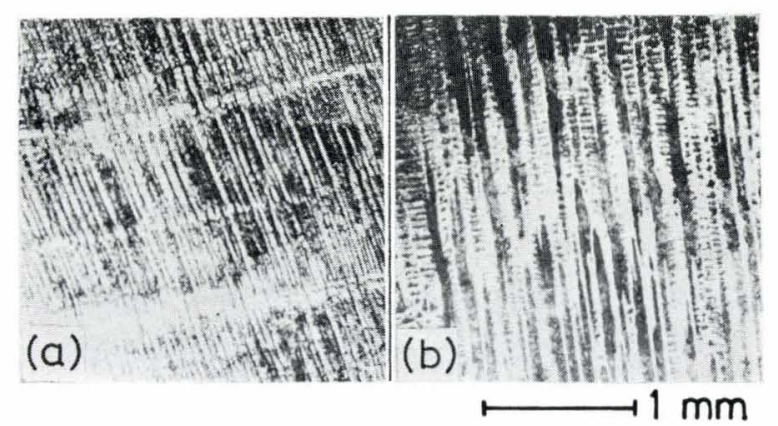

Distance from the initial solid-liquid interface: (a) $13 \mathrm{~mm}$ and (b) $22 \mathrm{~mm}$. In both photographs the macroscopic solidification direction is upward.

Photo. 2. Solidification structures of ingot B-1 degree of undercooling of the melt below the liquidus temperature was somewhat larger under the condition of T.C., both the values of $V$ and $G$ might become smaller.

The cooling velocities of $\mathrm{C}$ series ingots were also estimated from their primary dendrite arm spacings by the above method: in this case the value of $m c(k-$ 1) was taken to be $10^{\circ} \mathrm{C}$ from a phase diagram of $\mathrm{Fe}-$ Ni system. ${ }^{17}$ ) The relations between the cooling velocity and the distance from the initial solid-liquid interface of $\mathrm{C}$ series ingots except $\mathrm{C}$-2, were almost the same as those of $\mathrm{B}$ series ingots. In ingot C-2, however, the estimated cooling velocities were much low, by about $1 / 3$ to $1 / 5$, compared with those at the corresponding positions of the other ingots solidified under the condition of T.C. This is caused perhaps by an incomplete contact between the bottom of ingot and the water-cooled copper, because the material $\mathrm{C}$ is difficult to be wetted with the solder.

Although the cooling velocity of A series ingots could not be estimated from their solidification structures, it seems likely that the solidification conditions are almost the same as those shown in Fig. 3.

\section{Distribution of Inclusions}

The distribution of inclusions was measured along near the center line of the longitudinal cross section of ingot. In ingots melted without $\mathrm{Si}$ addition (A-1, A-3, B-1, B-3, C-1, C-3), almost all the inclusions were round particles having a diameter of $0.3 \sim 5 \mu \mathrm{m}$ and they located mainly in or near the intercellular or interdendritic region; which was clearly observed in ingot $\mathrm{A}-1$. In ingots deoxidized with $\mathrm{Si}$ (A-2, A-4, B-2, B-4, C-2, C-4), transparent round particles having a diameter of $1 \sim 10 \mu \mathrm{m}$ were randomly distributed. Point-like or rod-like inclusions having a diameter or a width of less than $2 \mu \mathrm{m}$, and being located in a row as shown in Photo. 3, were also observed in ingots A-2 and B-2. In some ingots, the average diameter of inclusion and the area percent of inclusions occupying the matrix tended to increase with increasing the distance from the initial solid-liquid interface. In the region between 15 $20 \mathrm{~mm}$ from the initial solid-liquid interface, the area percent of inclusions was smaller in ingots deoxidized with $\mathrm{Si}$, correspondingly roughly to the decrease in $\mathrm{O}$ content. The average diameter of inclusion in $\mathrm{B}$

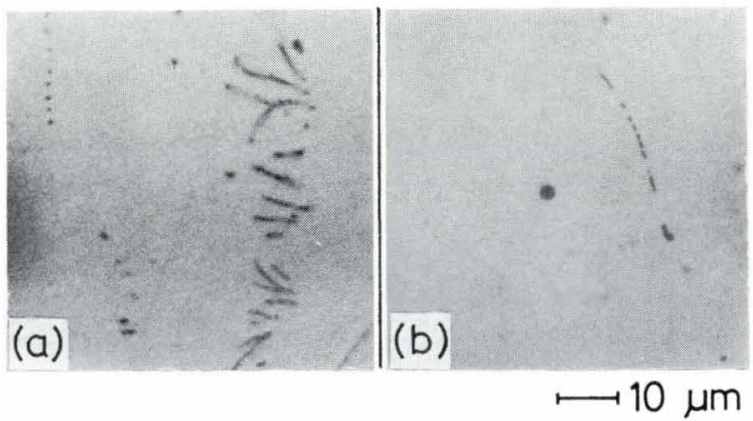

Photo. 3. Optical micrographs of point-like or rod-like inclusions observed in the cross section of ingots (a) A-2 and (b) B-2 
series ingots was significantly large compared with that in A series ingots; e.g., 1.8, 1.0, 2.5 and $1.5 \mu \mathrm{m}$ for ingots A-1, A-2, B-1 and B-2, respectively.

\section{Morphology of Inclusions}

\section{Inclusions in Ingots Melted without Si Addition}

Almost all the inclusions observed in this kind of ingots were roughly spherical regardless of the solidification conditions. Typical examples of the inclusions are shown in Photos. 4 (a) to (c). In ingots C-1 and C-3, however, some bamboo-like inclusions, as shown in Photo. 4 (d), were also observed.

\section{Inclusions in Ingots Deoxidized with $\mathbf{S i}$}

The shape of inclusion in this kind of ingots was different, depending upon the position, the constituent and the solidification condition of the ingot. The shapes were classified into the following eight types, of which typical examples are shown in Photo. 5.

Type I: Smooth spherical particles having a diameter of $2 \sim 10 \mu \mathrm{m}$, which were occasionally somewhat elongate along the macroscopic solidification direction of matrix, as shown in Photo. 5 (a) and at the lower right in Photo. 5 (b), respectively. Inclusions of this type, well-known as the primary silica inclusions, were observed at random in all the portion of the deoxidized ingots except ingot B-2

Type II: Smooth spherical particles having a diameter of less than $2 \mu \mathrm{m}$. Generally, they swarmed, sometimes together with larger particles, in a narrow region, as shown in Photos. 5 (c) and (d).

Type III: Short elongate inclusions as shown in Photos. 5 (e) and (f).

Type IV: Short elongate inclusions adjoining to a large spherical inclusion, as shown in Photos. 5 (g)

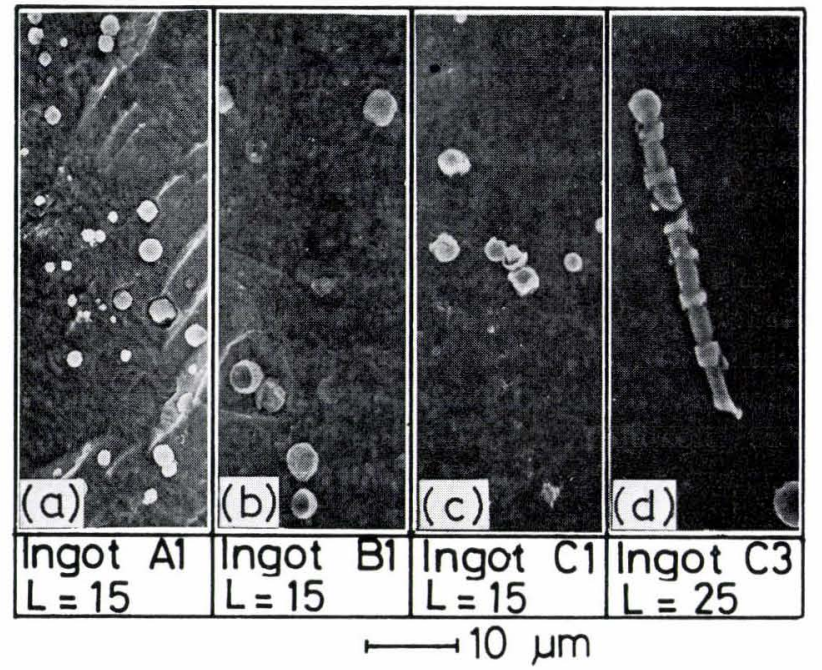

(a) $\sim$ (c): Inclusions commonly observed

(d): Bamboo-like inclusion

"L": the distance from the initial solid-liquid interface $(\mathrm{mm})$

Photo. 4. Scanning electron micrographs of inclusions in ingots melted without $\mathrm{Si}$ addition. In all photographs the macroscopic solidification direction is upward.

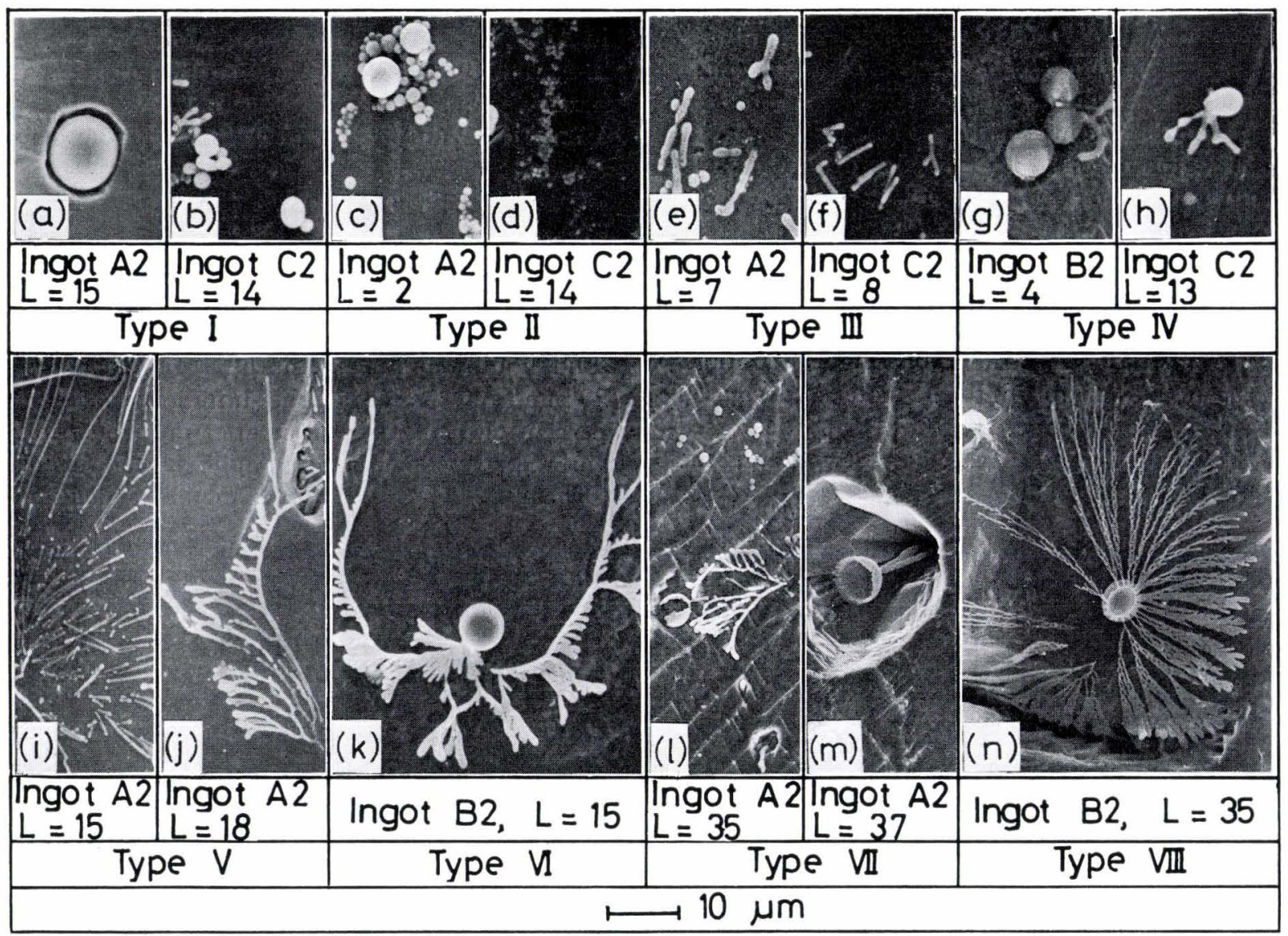

Photo. 5. Scanning electron micrographs showing eight types of inclusions in ingots deoxidized with Si. The meaning of "L" and the solidification direction are the same as in Photo. 4. 
and (h).

Type V: Elongate rod-like or dendritic inclusions, as shown in Photos. 5 (i) and (j). Inclusions of this type were frequently observed in the columnar structure region beyond by about $5 \mathrm{~mm}$ from the initial solid-liquid interface of ingot A-2

Type VI: Elongate dendritic inclusions grown from a lower part of a large spherical inclusion, downward initially and then sideways and upward, as shown in Photo. $5(\mathrm{k})$. Almost all the inclusions observed in the columnar structure region beyond by about $5 \mathrm{~mm}$ from the initial solid-liquid interface of ingot B-2 were classified into this type.

Type VII: Inclusions resembling a cracked ball or a sunflower at a tip of dendritic inclusion, as shown in Photos. $5(1)$ and $(m)$. Inclusions of this type were occasionally observed in the equiaxed structure region of ingot A-2.

Type VIII: Dendritic inclusions grown from several points of a large spherical inclusion, as shown in Photo. $5(\mathrm{n})$. Inclusions of this type were frequently observed in the equiaxed structure region of ingot B-2.

The types of inclusions typically observed are summarized in Table 3, against the position of ingot. The types of $\mathrm{V}$ and VI are the characteristic shapes of inclusions in the columnar structure region of ingots A-2 and B-2, respectively. Such pronounced dendritic inclusions were hardly observed in all of the ingots solidified under the condition of P.C. and in ingot C-2 which was solidified under the condition of T.C. but was low both in the $\mathrm{O}$ content and in the cooling velocity.

\section{Constituents and Structure of Dendritic Inclusions}

Electron probe microanalyses were performed on many dendritic inclusions. $\mathrm{Si}$ and $\mathrm{O}$ were clearly detected as shown in Photo. 6, while $\mathrm{S}, \mathrm{Mn}$ and $\mathrm{Al}$ were not detected. Thus, it was confirmed that these inclusions were composed of silica or silicate. Quantitative electron probe microanalyses on some dendritic inclusions indicated that the inclusions had a somewhat large ratio of $\mathrm{O} / \mathrm{Si}$ compared with a large spherical inclusion; e.g., one of the dendritic inclu-

Table 3. Summary of the types of inclusion typically observed in ingots deoxidized with $\mathrm{Si}^{*}$

\begin{tabular}{|c|c|c|c|c|c|}
\hline \multirow{2}{*}{$\begin{array}{c}\text { Ingot } \\
\text { No. }\end{array}$} & \multicolumn{5}{|c|}{ Distance from the initial solid-liquid interface $(\mathrm{mm})$} \\
\hline & $0 \sim 5$ & $5 \sim 10$ & $10 \sim 20$ & $20 \sim 25$ & $>25$ \\
\hline A-2 & I, II & $\underset{\mathrm{V}}{\mathrm{I}} \mathrm{II}, \mathrm{III}$, & I, V & $\mathrm{I}, \mathrm{V}$ & $\begin{array}{l}(\mathrm{I}, \mathrm{II} \\
\mathrm{V}, \mathrm{VII}) * *\end{array}$ \\
\hline B-2 & I, III, IV & VI & VI & VI & $(\mathrm{VIII}) * *$ \\
\hline $\mathrm{C}-2$ & I, II & I, II, III & $\begin{array}{l}\text { I, II, } \\
\text { III, IV }\end{array}$ & $\begin{array}{l}(\mathrm{I}, \mathrm{II} \\
\mathrm{III})^{* *}\end{array}$ & $\begin{array}{l}(\mathrm{I}, \mathrm{II} \\
\mathrm{III})^{* *}\end{array}$ \\
\hline A-4 & I, II & I, III & I & I & I \\
\hline B-4 & I & I & I & I & I, III \\
\hline C-4 & I & I & I & I & I \\
\hline
\end{tabular}

* Typical examples of the types I to VIII are shown in Photo. 5.

( )** Equiaxed structure region sions in ingot A-2 was regarded as an iron silicate being composed of about $90 \mathrm{~mol}^{\%}$ of $\mathrm{SiO}_{2}$ and $10 \mathrm{~mol}^{\%} \%$ of $\mathrm{FeO}$.

All of the selected-area transmission electron diffraction patterns of many dendritic inclusions, were so-called halo patterns, as shown in Photo. 7. From the results, it was concluded that almost all the dendritic inclusions in the present investigation were substantially amorphous.

\section{Discussion}

Pronounced dendritic inclusions were frequently observed in ingots A-2 and B-2 which were solidified under the condition of T.C., but hardly in ingots solidified under the condition of P.C., in spite of the

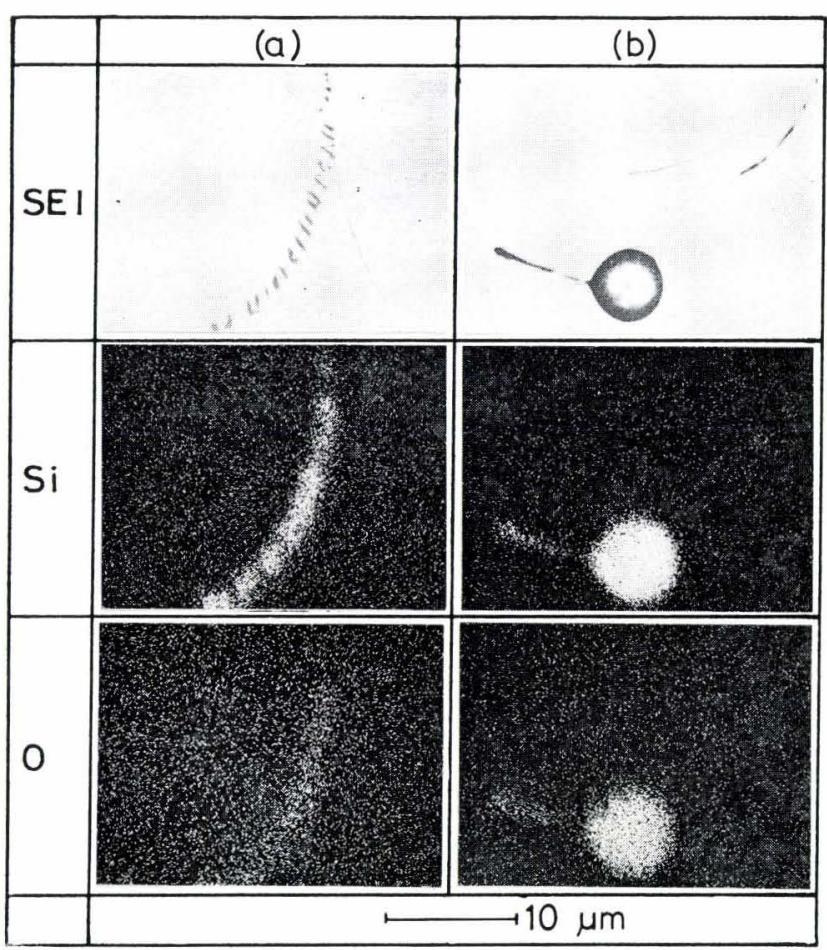

Photo. 6. Secondary electron images and X-ray images of Si$\mathrm{K} \alpha$ and $\mathrm{O}-\mathrm{K}_{\alpha}$ of (a) dendritic inclusions in ingot A-2, and (b) dendritic inclusions with a primary inclusion in ingot B-2

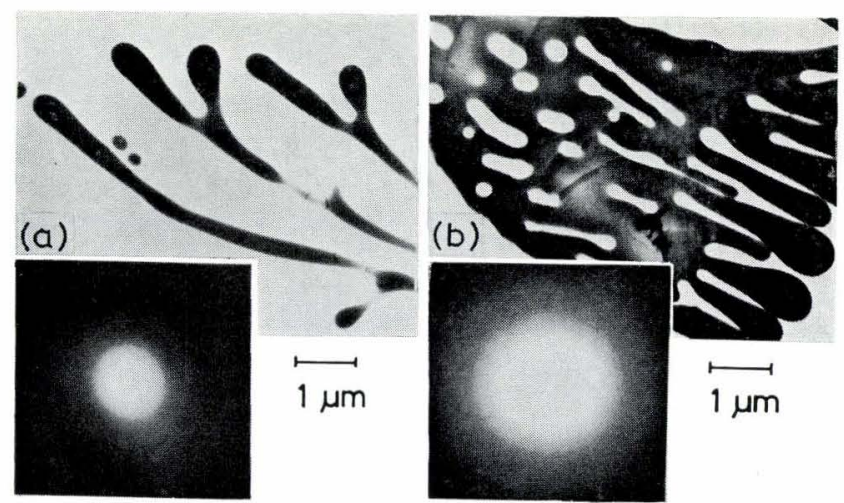

Photo. 7. Transmission electron micrographs and selected-area diffraction patterns of dendritic inclusions extracted from (a) ingot A-2 and (b) ingot B-2 
same order of $\mathrm{Si}$ content. The equilibria of $\mathrm{O}$ and $\mathrm{Si}$ in $\mathrm{Fe}$ and $\mathrm{Fe}-10 \mathrm{wt} \% \mathrm{Ni}$ alloy are shown in Fig. 4, which is constructed by using the data shown in Table 4 and on the assumptions that the data are applicable to the $\mathrm{Fe}-10 \% \mathrm{Ni}$ alloy down to temperatures far below the melting point of $\mathrm{Fe}$, and that the activities of deoxidation products do not change by $\mathrm{Ni}$. The activity of $\mathrm{Fe}$ in the alloy was taken as the molar fraction of $\mathrm{Fe}$. The contents of $\mathrm{O}$ and $\mathrm{Si}$ at the portion of $15 \sim 20 \mathrm{~mm}$ from the initial solidliquid interface of ingot are also plotted in Fig. 4. The $\mathrm{O}$ contents of ingots $\mathrm{A}-2$ and $\mathrm{B}-2$ are about 1.4 and 2.3 times of the amount of $\mathrm{O}$ equilibrating to $\mathrm{Si}$ at the liquidus temperature, respectively, while those of ingots A-4 and B-4 are about 0.5 and 0.7 times, respectively. This strongly suggests that one of the causes of the formation of dendritic inclusions is the incomplete deoxidation of $\mathrm{Fe}$ with $\mathrm{Si}$ during solidification.

The $\mathrm{O}$ contents of ingots A-3, A-4, B-3 and B-4, which were solidified under the condition of P.C., are significantly smaller than the equilibrium $\mathrm{O}$

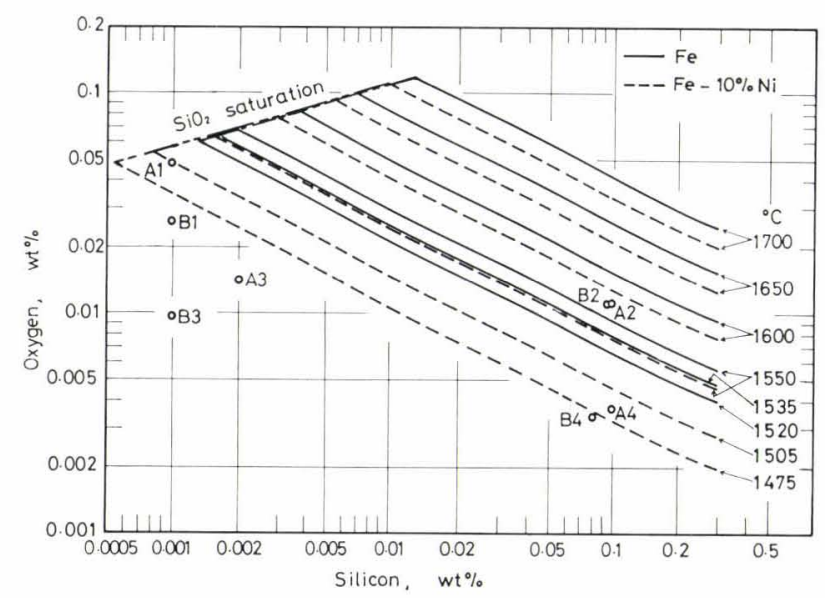

Fig. 4. Si-O equilibria in $\mathrm{Fe}$ and $\mathrm{Fe}-10 \mathrm{wt} \% \mathrm{Ni}$ alloy

Table 4. Data used to draw Fig. 4

Data

Ref. No.

\begin{tabular}{|c|c|}
\hline & Data \\
\hline \multicolumn{2}{|c|}{ Reaction } \\
\hline \multirow[t]{2}{*}{ (I) } & $\underline{\mathrm{Si}}+2 \underline{\mathrm{O}}=\mathrm{SiO}_{2}(s)$ \\
\hline & $\Delta G^{\circ}=-140540+53.79 T(\mathrm{cal} / \mathrm{mol})$ \\
\hline \multirow[t]{2}{*}{ (II) } & $\mathrm{Fe}(l)+\underline{\mathrm{O}}=\mathrm{FeO}(l)$ \\
\hline & $\Delta G^{\circ}=-28130+11.91 T(\mathrm{cal} / \mathrm{mol})$ \\
\hline \multirow[t]{3}{*}{ (III) } & $\underline{\mathrm{Si}}+2 \mathrm{FeO}(l)=2 \mathrm{Fe}(l)+\mathrm{SiO}_{2}$ (sat.) \\
\hline & $\Delta G^{\circ}=-84280+29.97 T(\mathrm{cal} / \mathrm{mol})$ \\
\hline & Eq. (III $)=E q \cdot(\mathrm{I})-2 \times$ Eq. (II) \\
\hline \multicolumn{2}{|c|}{ Interaction coefficient } \\
\hline \multicolumn{2}{|c|}{$e_{\mathrm{Si}}^{\mathrm{Si}}=0.11$} \\
\hline \multicolumn{2}{|c|}{$e_{\mathrm{Si}}^{\mathrm{O}}=-0.237$ (calculated from $\left.e_{\mathrm{O}}^{\mathrm{Si}}\right)$} \\
\hline \multicolumn{2}{|c|}{$e_{\mathrm{O}}^{\mathrm{O}}=-1750 / T+0.76$} \\
\hline \multicolumn{2}{|c|}{$e_{\mathrm{O}}^{\mathrm{Si}}=-0.137$} \\
\hline \multicolumn{2}{|c|}{$e_{\mathrm{Si}}^{\mathrm{Ni}}=0.005$} \\
\hline \multicolumn{2}{|c|}{$e_{\mathrm{o}}^{\mathrm{N} 1}=0.006$} \\
\hline \multicolumn{2}{|c|}{ Activity } \\
\hline $\log a_{\mathrm{F}}$ & (l) $($ in Eq. $(\mathrm{III}))=300 / T-0.590$ \\
\hline
\end{tabular}

20)
21)
$18)$
$22)$
$14)$
$23)$

concentrations at their liquidus temperatures. This is perhaps caused by the slightly reducing atmosphere, the alumina crucible used, ${ }^{6,24)}$ the macrosegregation and the floating up of oxide inclusions during unidirectional solidification. On the assumptions that there is no diffusion in solid, that the solute concentration in liquid is always homogeneous, and that there is no interaction between solutes, the variation of the concentration of solute in the remaining liquid, $C_{L}$, with the fraction of solid, $f_{S}$, can be calculated by so-called Scheil equation, ${ }^{16)}$

$$
C_{L}=C_{O}\left(1-f_{S}\right)^{(k-1)}
$$

where, $C_{0}$ : the initial concentration

$k$ : the equilibrium distribution coefficient of solute.

If the above assumptions are satisfied and the solidliquid interface is always planar, from the values of $k$ shown in Table 5 and the above equation, the $\mathrm{O}$ content in the portion of $25 \sim 30 \mathrm{~mm}$ from the initial solidliquid interface is expected to be about 1.8 times of that in the portion of $15 \sim 20 \mathrm{~mm}$ from the initial solid-liquid interface, since the length of the initial molten zone is about $40 \mathrm{~mm}$. In ingots A-1, B-1, B-3 and $\mathrm{B}-4$, the $\mathrm{O}$ content in the former portion is about $1.4 \sim 1.7$ times of that in the latter portion. Although actually the above assumptions are not completely satisfied during solidification in this experiment, it seems that some degree of macrosegregation, especially of $\mathrm{O}$ whose value of $k$ is very small as shown in Table 5, are there in all of the ingots used. During cellular (or dendritic) solidification, the $\mathrm{O}$ concentration just ahead of the solid-liquid interface in the intercellular region would be very large. As the solubility of $\mathrm{O}$ in liquid $\mathrm{Fe}$ decreases with decreasing temperature, e.g., $0.23 \mathrm{wt} \%$ at $1600{ }^{\circ} \mathrm{C}$ and $0.16 \mathrm{wt} \%$ at $1523^{\circ} \mathrm{C},{ }^{17,19)}$ when the temperature of melt is low as under the condition of P.C., iron oxides would be formed at an early stage of cellular solidification; therefore, the chance of floating up of the oxides from the intercellular region would be large.

Dendritic inclusions of the type $V$ must be nucleated and grown by a supersaturation in the intercellular or interdendritic region, or grown continuously from small primary inclusions in the region. The free energy change, $\Delta G_{\mathrm{hom}}$, and the supersaturation, $K / K_{e}$, necessary for homogeneous nucleation of inclusions can be expressed as follows: ${ }^{41}$

$$
\Delta G_{\mathrm{hom}}=-2.7 v\left[\frac{\sigma^{3}}{k T \log (A / I)}\right]^{1 / 2}=-R T \ln \left(K / K_{e}\right)
$$

where, $v$ : the molar volume of the nucleus of inclu-

Table 5. Equilibrium distribution coefficient, $k$, of some elements in $\mathrm{Fe}$, used in the present discussion

\begin{tabular}{l|cc|cc|c}
\hline \multirow{2}{*}{ Element } & \multicolumn{2}{|c|}{$\mathrm{O}$} & \multicolumn{2}{|c|}{$\mathrm{Si}$} & $\mathrm{Ni}$ \\
\hline Solidification & $\delta$ & $\gamma$ & $\delta$ & $\gamma$ & $\gamma$ \\
\hline$k$ & 0.022 & 0.03 & 0.77 & 0.54 & 0.85 \\
\hline Ref. No. & $25)$ & $26)$ & $27)$ & $28)$ & $28)$ \\
\hline
\end{tabular}


sion

$\sigma:$ the interfacial tension between the nucleus and liquid Fe

$k$ : Boltzmann's constant

$T$ : temperature

$R$ : gas constant

$A$ : a frequency factor

$I$ : the rate of formation of nuclei per $\mathrm{cm}^{3}$ of metal per second.

$\kappa / K_{e}$ is expressed as:

$$
\begin{aligned}
& \frac{\left(f_{\mathrm{si}} \cdot \% \mathrm{Si}\right) \times\left(f_{o} \cdot \% \mathrm{O}\right)^{2}}{\left(f_{\mathrm{Si}} \cdot \% \mathrm{Si}\right)_{\mathrm{eq}} \times\left(f_{o} \cdot \% \mathrm{O}\right)_{\mathrm{eq}}^{2}} \text { for } \mathrm{SiO}_{2} \\
& \text { or } \frac{\left(f_{o} \cdot \% \mathrm{O}\right)}{\left(f_{o} \cdot \% \mathrm{O}\right)_{\mathrm{eq}}} \text { for } \mathrm{FeO}
\end{aligned}
$$

where, $f_{\mathrm{Si}}, f_{0}$ : the activity coefficients of $\mathrm{Si}$ and $\mathrm{O}$, respectively.

$\Delta G_{\mathrm{hom}}$ and $K / K_{e}$ at $I=1$ are represented by $\Delta G_{\mathrm{hom}}^{*}$ and $\left(K / K_{e}\right)^{*}$ respectively, then the radius of nucleus, $r^{*}$, is expressed as

$$
r^{*}=-2 \sigma v / \Delta G_{\mathrm{hom}}^{*}
$$

By taking the values of $A$ as $10^{28}$ for $\mathrm{SiO}_{2}(s)$ and $10^{30}$ for $\mathrm{FeO}(l),{ }^{4)}$ and the values of $v$ as 27.3 for $\mathrm{SiO}_{2}(s)^{29}$ and $15.8 \mathrm{~cm}^{3} / \mathrm{mol}$ for $\mathrm{FeO}(l),{ }^{30,31)}$ respectively, $\Delta G_{\text {hom }}^{*}$ and $\left(K / K_{e}\right)^{*}$ for $\mathrm{SiO}_{2}(s)$ and $\mathrm{FeO}(l)$ in $\mathrm{Fe}$ at $1535^{\circ} \mathrm{C}$ were calculated against several presumed values of $\sigma,{ }^{4,5)}$ and are shown in Table 6 . From the table, it is seen that $\mathrm{FeO}(l)$ can nucleate homogeneously at much less degree of supersaturation compared with $\mathrm{SiO}_{2}(s)$.

The ratio of average width of area almost free from inclusions to the average distance between adjacent cell boundaries where inclusions were situated in a line, was about 0.97 in the region between $10 \sim 20 \mathrm{~mm}$ from the initial solid-liquid interface of ingot A-2. The ratio was determined perpendicularly to the macroscopic solidification direction. By assuming that the ratio is the fraction of solid when the inclusions nucleated, that there is no diffusion in solid, that the solute concentration in liquid is always homogeneous, and that the concentrations of $\mathrm{O}$ and $\mathrm{Si}$ in the liquid are the same as those contents shown in Table 2, and they do not react with each other until the inclusions nucleate, the value of $K / K_{e}$ for $\mathrm{SiO}_{2}(s)$ at $1535^{\circ} \mathrm{C}$ in the

Table 6. Free energy change, $\Delta G_{\mathrm{hom}}^{*}$, and supersaturation, $\left(K / K_{e}\right)^{*}$, necessary for homogeneous nucleation, and critical radius of nucleus, $r^{*}$, of $\mathrm{SiO}_{2}(s)$ and $\mathrm{FeO}(l)$ in $\mathrm{Fe}$ at $1535^{\circ} \mathrm{C}$

\begin{tabular}{c|cclc}
\hline & $\begin{array}{c}\sigma \\
\left(\mathrm{erg} / \mathrm{cm}^{2}\right)\end{array}$ & $\begin{array}{c}\Delta G_{\text {nom }}^{*} \\
(\mathrm{kcal} / \mathrm{mol})\end{array}$ & $\left(K / K_{e}\right)^{*}$ & $r *(\AA)$ \\
\hline $\mathrm{SiO}_{2}(s)$ & 1200 & -27.7 & $2.23 \times 10^{3}$ & 5.7 \\
& 1250 & -29.5 & $3.64 \times 10^{3}$ & 5.5 \\
& 1300 & -31.2 & $5.96 \times 10^{3}$ & 5.4 \\
\hline $\mathrm{FeO}(l)$ & 100 & -0.38 & 1.11 & 20.0 \\
& 250 & -1.49 & 1.51 & 12.8 \\
& 400 & -3.02 & 2.32 & 10.1
\end{tabular}

intercellular region was calculated to be $2.38 \times 10^{3}$. If the interfacial tension between $\mathrm{SiO}_{2}(s)$ and liquid $\mathrm{Fe}$ is less than $1200 \mathrm{erg} / \mathrm{cm}^{2}$, the dendritic inclusions in ingot A-2 can be regarded as those nucleated homogeneously as $\mathrm{SiO}_{2}(s)$. However, because the value of $K / K_{e}$ for $\mathrm{FeO}(l)$ at $1535^{\circ} \mathrm{C}$ in the intercellular region is 1.69, if the values of $\sigma$ are 1300 and $250 \mathrm{erg} /$ $\mathrm{cm}^{2}$ for $\mathrm{SiO}_{2}(s)$ and $\mathrm{FeO}(l)$ respectively, ${ }^{5)} \mathrm{FeO}(l)$ would nucleate before the nucleation of $\mathrm{SiO}_{2}(s)$. Thus, it seems that the dendritic inclusions possibly nucleate as $\mathrm{FeO}(l)$ or at least liquid silicate, and then $\mathrm{FeO}(l)$ or liquid silicate is reduced by $\mathrm{Si}$ diffusing to it. For the dendritic growth of the nuclei, a supersaturated zone having a suitable gradient of the degree of supersaturation seems to be needed, because if not so, the nuclei would grow spherically. Such a zone is perhaps formed mainly by the segregation of O. As the melting point of $\mathrm{FeO}$ is below $1400^{\circ} \mathrm{C}^{17}$ ) and the lowest melting point in $\mathrm{FeO}-\mathrm{SiO}_{2}$ system is below $1200^{\circ} \mathrm{C},{ }^{22)}$ the nuclei will continue to grow dendritically even after the surrounding material has already solidified. Inclusions of the type VII, as shown in Photos. 5 (1) and (m), suggest the above process: i.e., the inclusion at a tip of dendritic inclusion was formed perhaps by the reducing reaction with $\mathrm{Si}$ having continued until the liquid ahead of the reaction interface solidified. When the temperature gradient is very large and the rate of solidification is very small as in a region near the initial solidliquid interface, or the $\mathrm{O}$ concentration is small as in ingots solidified under the condition of P.C. and ingot C-2, the nuclei do not grow dendritically perhaps because the suitable supersaturated zone is not formed. In this case, the secondary inclusions are fine spheres or short elongate ones as shown in Photos. 5 (c) to (f).

The free energy change necessary for heterogeneous nucleation, $\Delta G_{\mathrm{het}}$, is expressed as follows: ${ }^{4)}$

$$
\Delta G_{\mathrm{het}}=\Delta G_{\mathrm{hom}} \times \frac{1}{4}(2+\cos \theta)(1-\cos \theta)^{2}
$$

where $\theta$ is the contact angle of nucleus of a spherical cap on a planar substrate. Thus, the more an inclusion apt to wet a primary inclusion, the more easily the inclusion nucleates on the primary inclusion: if the supersaturation around a spherical primary inclusion is homogeneous, the primary inclusion would grow as the spherical shape. When the gradient of the degree of supersaturation in liquid downward from a primary inclusion is sufficiently large, and the supersaturated zone is moving upward at a relatively high speed, an inclusion nucleates at a lower point of the surface of the primary inclusion, and grows downward initially, and then sideways and upward, depending on the movement of the supersaturated zone: which is clearly seen in Photo. $5(\mathrm{k})$. The average length between the point of the origin and the downward tips of the dendritic inclusions observed in the region around $15 \mathrm{~mm}$ from the initial solid-liquid interface of ingot B-2, was about $20 \mu \mathrm{m}$. If the position of downward tips of the inclusion was limited by the solidification front of the matrix, and 
the downward growth speed of the tips was the same order as the rising speed of the solidification front, there must be a sufficient degree of supersaturation for the heterogeneous nucleation of the dendritic inclusion, in the liquid ahead of about $40 \mu \mathrm{m}$ from the solidification front, since the solidification front in this region was moving at a speed of about $2.5 \mathrm{~mm} / \mathrm{min}$ (Fig. 3 (a)). From the temperature gradient shown in Fig. 3 (c) and the difference between the liquidusand solidus-temperatures of $\mathrm{Fe}-10 \% \mathrm{Ni}$ alloy, it is reasonable to consider that the liquid up to about $40 \mu \mathrm{m}$ ahead of the solidification front was much more supercooled by $\mathrm{Ni}$ besides the supercooling by other elements, and a larger degree of supersaturation would occur in this region. Therefore, a liquid zone which has a suitable gradient of a sufficient degree of supersaturation perhaps is a cause of the formation of dendritic inclusions of the type VI.

For the purpose of confirming the above consideration, ingots $\mathrm{A}-10$ and $\mathrm{B}-10$, of which chemical compositions were the same order as those of ingots $\mathrm{A}-2$ and $\mathrm{B}-2$, respectively, were solidified under the condition of P.C. with the withdrawal speed of induction heating coil of $10 \mathrm{~mm} / \mathrm{min}$. From the primary dendrite arm spacing of ingot B-10, the cooling velocities of the respective positions of the ingot were between those solidified under the conditions of T.C. and P.C. with the withdrawal speed of induction coil of $1.7 \mathrm{~mm} / \mathrm{min}$. Although the rate of solidification could not be determined precisely, it seemed to be about $10 \mathrm{~mm} / \mathrm{min}$ in average: thus, the temperature gradient is small, by about $1 / 5$, compared with those of ingots A-2 and B-2. As shown in Photo. 8, dendritic inclusions of the type VI were observed in both the ingots $\mathrm{A}-10$ and $\mathrm{B}-10$. Compared with the inclusions in ingot $\mathrm{B}-2$, the dendritic inclusions in ingot B-10 were slender and somewhat long and the primary inclusions were small. Dendritic inclusions grown from a primary inclusion in ingot A-10 were short and usually grown only to one direction. The temperature distributions near the macroscopic solidliquid interface of ingots A-10 and B-10 are schematically shown in Fig. 5, compared with those of ingots A-2 and B-2, respectively, by using the estimated temperature gradients. The results perhaps prove that an increase of the degree of supercooling caused by the decrease of temperature gradient, results in an increase of the degree of supersaturation ahead of the solid-liquid interface: which results in the inclusions of the type VI. When the supersaturation is large and the supersaturated zone hardly moves, as in a region solidifying lastly, the dendritic inclusions nucleate at several points on the surface of a primary inclusion and grow so as to consume the supersaturation, as shown in Photo. 5 (n).

Dendritic inclusions of the type $\mathrm{V}$ were also observed in ingot A-10, while almost all the dendritic inclusions in B series ingots were classified into the type VI. This suggests that the aptness of the formation of the type VI-inclusions in B series ingots is caused not only by the supercooling by $\mathrm{Ni}$ but also by a decrease of $\mathrm{O}$ concentration in the intercellular or interdendritic liquid by the $\mathrm{Ni}$ concentrated in the region. ${ }^{13)}$

Although Hilty and Crafts $^{2)}$ reported that dendritic inclusions were identified as crystals of crystobalite, almost all the dendritic inclusions in the present investigation were regarded as glassy; the reason is not clear. However, it can be concluded that the formation of dendritic inclusions in $\mathrm{Fe}$ deoxidized with $\mathrm{Si}$ is not caused by the crystallographic growth direction of the inclusions but by a suitable gradient of a sufficient degree of supersaturation during solidification of $\mathrm{Fe}$.

\section{Summary}

For the purpose of clarifying the formation mechanism of dendritic inclusions in $\mathrm{Fe}$ deoxidized with

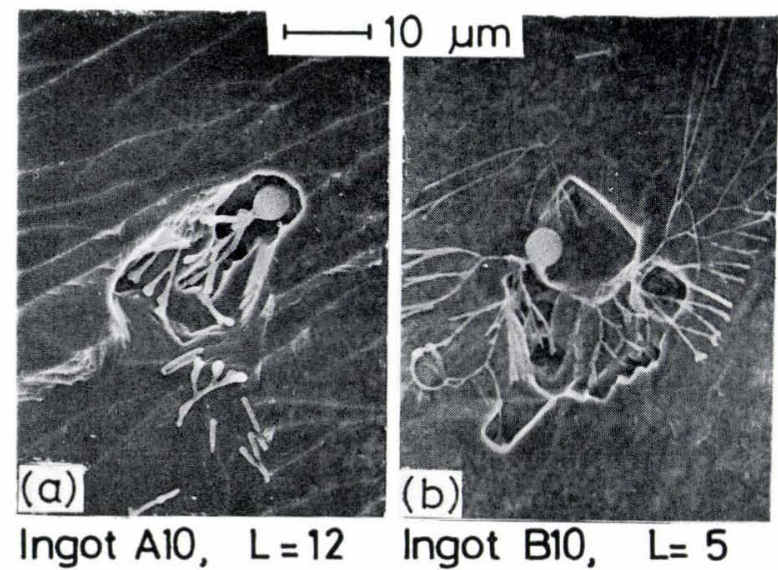

Photo. 8. Scanning electron micrographs of dendritic inclusions grown from a spherical primary inclusion observed in ingots A-10 and B-10. The meaning of "L " and the solidification direction are the same as in Photo. 4.

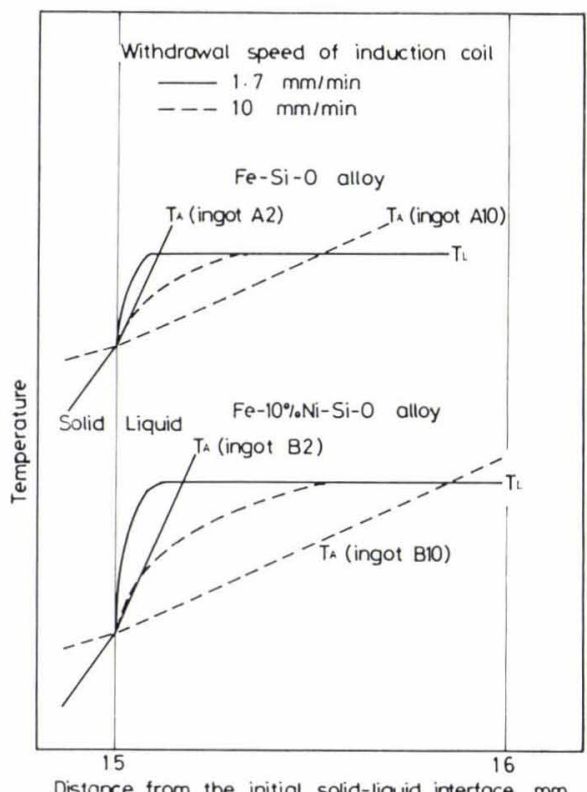

$T_{A}$ : Actual temperature

$T_{L}$ : Liquidus temperature

Fig. 5. Schematic representation of the temperature distribution near the macroscopic solid-liquid interface. The interface is assumed to be planar. 
$\mathrm{Si}$, the morphology of inclusions in $\mathrm{Fe}, \mathrm{Fe}-10 \% \mathrm{Ni}$ and $\mathrm{Fe}-40 \% \mathrm{Ni}$ alloys, which were deoxidized with $0.1 \mathrm{wt} \%$ of $\mathrm{Si}$ and solidified unidirectionally under specified conditions, have been investigated.

(1) Dendritic inclusions were frequently observed in ingots containing a large amount of $\mathrm{O}$ but hardly in ingots whose $\mathrm{O}$ content was smaller than that equilibrating to the amount of $\mathrm{Si}$ at the liquidus temperature.

(2) The dendritic inclusions were classified roughly into two types: one is those existing mainly in the intercellular or interdendritic region of matrix, and the other is those grown from a spherical primary inclusion.

(3) From the solidification conditions, inclusions of the former type were formed perhaps by a suitable gradient of the supersaturation in liquid at the intercellular or interdendritic region of matrix. Inclusions of the latter type seemed to be formed by a suitable gradient of supersaturation in liquid around the primary inclusion.

(4) By electron probe microanalyses and selectedarea transmission electron diffraction experiments on the dendritic inclusions, it was confirmed that they were composed of silica or silicate and substantially amorphous.

(5) From the above results, it can be concluded that the dendritic inclusions in $\mathrm{Fe}$ deoxidized with $\mathrm{Si}$ is not formed by the crystallographic growth direction of the inclusions but formed by a suitable gradient of a sufficient degree of supersaturation, which is caused mainly by the segregation of $\mathrm{O}$ and/or caused by supercooling during solidification of Fe.

\section{Acknowledgements}

The authors wish to acknowledge to Mr. T. Hattori and Mr. G. Sato (both were the students of Tokai University) for the co-operation to a part of the present work. They are also indebted to many members of Melting and Rolling Section, Physical Analysis Section and Chemical Analysis Section of National Research Institute for Metals, for the preparation of raw materials, the electron microscopy, the electron probe microanalyses, and the chemical analyses of specimens.

\section{REFERENCES}

1) C. A. Zapffe and C. E. Sims: Trans. AIME, 154 (1943), 192.

2) D. C. Hilty and W. Crafts: Trans. AIME, 188 (1950), 425.

3) W. A. Fischer and M. Wahlster: Arch. Eisenhüttenw., 29 (1958), 1
4) M. L. Turpin and J. F. Elliott: JISI, 204 (1966), 217.

5) G. Forward and J. F. Elliott, with an appendix by T. Kuwabara and J. F. Elliott: Met. Trans., 1 (1970), 2889.

6) R. Sakagami, C. Kawasaki, I. Suzuki and K. Sato: Tetsuto-Hagané, 55 (1969), 550.

7) R. Sakagami and T. Sasai: Tetsu-to-Hagané, 57 (1971), 1953.

8) M. Myers and M. C. Flemings: Met. Trans., 3 (1972), 2225.

9) H. Hosoda, N. Sano and Y. Matsushita: Trans. ISIJ, 16 (1976), 115.

10) M. C. Flemings, D. R. Poirier, R. V. Barone and H. D. Brody: JISI, 208 (1970), 371.

11) K. Kishitake and T. Okamoto: Tetsu-to-Hagané, 63 (1977), 425.

12) e.g., L. S. Darken: Trans. Met. Soc. AIME, 239 (1967), 80.

13) H. A. Wriedt and J. Chipman: Trans. AIME, 203 (1955), 477.

14) H. A. Wriedt and J. Chipman: J. Metals, 8 (1956), 1195.

15) H. Takada, I. Bessho and T. Itoh: Tetsu-to-Hagané, 62 (1976), 1319.

16) e.g., M. C. Flemings: Solidification Processing, McGrawHill Inc., New York, (1974).

17) M. Hansen: Constitution of Binary Alloys, 2nd Ed., McGraw-Hill Book Co., New York, (1958).

18) Y. Matoba, K. Gunji and T. Kuwabara: Tetsu-to-Hagané, 45 (1959), 1328.

19) H. Sakao and K. Sano: Report of the 19th Committee, Japan Society for the Promotion of Science, Rep. No. 19 8370 , (1970).

20) F. Woolley and J. F. Elliott: Trans. Met. Soc. AIME, 239 (1967), 1872.

21) H. Sakao and K. Sano: J. Japan Inst. Metals, 23 (1959), 671.

22) J. F. Elliott, M. Gleiser and V. Ramakrishna: Thermochemistry for Steelmaking, II, Addison-Wesley Pub. Co. Inc., Mass., (1963).

23) R. Schuhmann, Jr. and P. J. Ensio: J. Metals, 3 (1951), 401 .

24) K. Suzuki, S. Ban-ya and T. Fuwa: Tetsu-to-Hagané, 56 (1970), 20.

25) W. A. Fischer, H. Spitzer and M. Hishinuma: Arch. Eisenhüttenw., 31 (1960), 365.

26) J. Chipman and J. F. Elliott: Electric Furnace Steelmaking, II, ed. by C. E. Sims, John Wiley \& Sons, New York, (1963), 99.

27) W. A. Fischer and H. Frye: Arch. Eisenhüttenw., 41 (1970). 293.

28) T. Wada and H. Wada: Preprint of the 61st Meeting of Japan Inst. Metals, Oct., 1967, Sapporo, (1967), 174.

29) J. O'M. Bockris, J. W. Tomlinson and J. L. White: Trans. Faraday Soc., 52 (1956), 299.

30) J. Henderson, R. G. Hudson, R. G. Ward and G. Derge: Trans. Met. Soc. AIME, 221 (1961), 807.

31) D. R. Gaskell and R. G. Ward: Trans. Met. Soc. AIME, 239 (1967), 249. 